known to be related, although consanguinity cannot be completely ruled out because the father was adopted. They were both Mormons, in whom kinship coefficients and genetic heterogeneity are low. ${ }^{8}$ The significance of the parental history of drug ingestion and the maternal minor chromosomal variant is unknown.

The authors wish to express their appreciation to Dr Marylou Buyse of the Center for Birth Defects Information Service for assistance in syndrome identification, and to $\mathrm{Dr}$ Blanche Bobbitt for editing the manuscript.

\section{References}

1 Neu RL, Kajii T, Gardner LI, Nagyfy SF, King S. A lethal syndrome of microcephaly with multiple congenital anomalies in three siblings. J Pediatr 1971;47:610-2.

2 Laxova R, Ohara PT, Timothy JAD. A further example of a lethal autosomal recessive condition in sibs. $J$ Ment Defic Res 1972;16:139-43.
${ }^{3}$ Povysilova V, Macek M, Salichova J, Seemanova E. Letalni syndrom mnonocetnych malformaci u tri sourozencu. Cesk Pediatr 1976;31:190-4.

4 Gennady IL, Lurie IW, Ostrowskaja TI, et al. Brief clinical observations: the Neu-Laxova syndrome-a distinct entity. Am J Med Genet 1979;3:261-7.

5 Curry CJR, Laurence KM, Scott CI, Opitz J, Hall JG. Further delineation of the Neu-Laxova syndrome. Clin Res $1981 ; 29: 130$ A.

6 Magenis RE, Hecht F, Lovrien EW. Heritable fragile site on chromosome 16: probable localization of haptoslobin locus in man. Science 1970;170:85-7.

7 Drets ME, Cardoso JH, Delfino A H, Carrace J. Familial normal/partial trisomy 16 with selective endoreplication in malformed proband. Cytogenetics 1970;9:333-50.

8 Jorde LB. The genetic structure of the Utah Mormons: migration analysis. Hum Biol 1982;54:583-97.

Correspondence and requests for reprints to $\mathrm{Dr}$ Susan Beckwitt Turkel, Department of Pathology, Los Angeles County-USC Medical Center, Women's Hospital Room 1-M-19, Los Angeles, California 90033, USA.

\title{
Intestinal obstruction and cystic fibrosis: antenatal ultrasound appearance
}

\author{
J SHALEV, R NAVON*, D URBACH†, S MASHIACH, AND B GOLDMAN* \\ Department of Obstetrics and Gynecology, *the Institute of Human Genetics, and $\dagger$ the Department of \\ Neonatology, Chaim Sheba Medical Center, Sackler School of Medicine, Tel-Aviv University, Tel-Hashomer, \\ Israel.
}

SUMMARY The diagnosis of cystic fibrosis in utero is based on amniotic fluid analysis. False negative results of this method underline the importance of antenatal ultrasonography to detect intestinal obstruction in affected fetuses.

Cystic fibrosis, the most common autosomal recessive genetic disorder in Caucasians, occurs in about one in 1600 births and follows simple autosomal recessive transmission. The disease affects glands and results in abnormal mucus secretion. As a result, intestinal obstruction resulting from meconium abnormality is often observed. Intrauterine diagnosis of cystic fibrosis using intestinal obstruction as a sonographic marker in a late stage of pregnancy is reported.

\section{Case report}

A 32 -year-old gravida 6 , para 4 , who had previously given birth to a child with cystic fibrosis, underwent

Received for publication 5 October 1982.

Accepted for publication 8 November 1982. sonographic examination and amniocentesis at 21 weeks' gestation. She had previously had two healthy children, one pregnancy was aborted after measles infection, and one child died at the age of 5 months of cystic fibrosis. The fifth pregnancy was terminated at 24 weeks' gestation as amniocentesis showed cystic fibrosis in the fetus (figure). In the present pregnancy, amniotic fluid analysis by Hoesli's method was negative' ${ }^{1}$ and a 'normal' fetus was diagnosed. On routine sonographic scanning at 17 and 21 weeks' gestation no pathological findings were observed. At 33 weeks' gestation ultrasonography showed overdistended bowel loops and polyhydramnios. The stomach, both kidneys, and the bladder were of normal shape. Repeated sonography at 35 and 37 weeks' gestation showed a similar picture. Small bowel obstruction was suspected. At 39 weeks a female infant weighing $2900 \mathrm{~g}$ was delivered spontaneously with an Apgar score of 10 at 1 and 5 minutes. The neonate appeared normal except for gross abdominal distension. On the first day of life meconium was not passed. Plain abdominal $x$-ray revealed small bowel dilation. Barium enema showed microcolon. Eight days of 


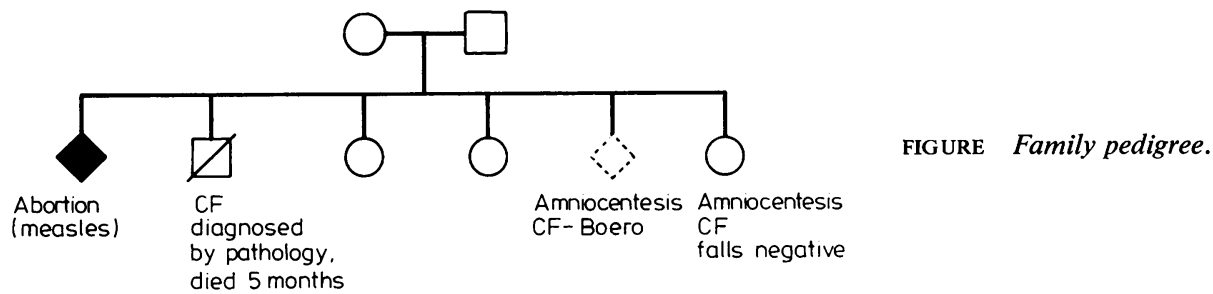

repeated gastrographin enemas eventually caused the passage of a meconium stool. Plain abdominal $x$-ray then showed normal air distribution. The sweat test on the first, third, and fifth days of life indicated cystic fibrosis.

\section{Discussion}

Newborn infants with cystic fibrosis have abnormal mucus secretion which can cause intestinal obstruction. Meconium plug syndrome and meconium ileus have been noticed after birth in approximately $7 \%$ of affected neonates. ${ }^{2}$ Twelve cases of meconium peritonitis were retrospectively reviewed by Finkel and Solvis, ${ }^{3}$ out of which five infants had cystic fibrosis. Knox et $a l^{4}$ reported a case of volvulus associated with massive abdominal distension causing obstructed labour in a neonate with cystic fibrosis. In our case intestinal obstruction, identified as multiple fluid filled bowel loops, was observed on routine sonographic scanning at 33 weeks' gestation. The fetal bowel, unlike that of the adult, is filled with fluid rather than gas, and therefore can be examined by ultrasound. Antenatal demonstration of overdistended bowel loops (bowel atresia) or fetal ascites combined with peritonea! calcification (meconium peritonitis) indicate the value of ultrasonography in detecting fetal abnormalities associated with cystic fibrosis. However, meconium plug syndrome may also be present with hypotonia, hypermagnesaemia, sepsis, hypothyroidism, and Hirschsprung's disease. ${ }^{2}$ This should obviously be taken into consideration when evaluating the sonographic findings. At present no accurate test for antenatal detection of cystic fibrosis is valid. ${ }^{15}$ In our clinic, false negative results of amniotic fluid examinations for cystic fibrosis show that all women with cystic fibrosis identified in previous children, sibs, or first cousins are at risk and their pregnancy should be closely followed by ultrasound examination. Sophisticated sonographic technology may detect intestinal pathology which may affect the management of the pregnancy and mode of delivery and improve postnatal care.

\section{References}

1 Hoesli P, Erickson RP, Vogt E. Prospects for prenatal diagnosis of cystic fibrosis: induction of biochemical abnormalities in fibroblasts from patients with cystic fibrosis by a urinary glycoprotein. Biochem Biophys Res Commun 1976;73:209-16.

2 Rosenstein BJ, Langbaum TS. Incidence of meconium abnormalities in newborn infants with cystic fibrosis. Am J Dis Child 1980;134:72-4.

3 Finkel LI, Solvis TL. Meconium peritonitis, intraperitoneal calcifications and cystic fibrosis. Pediatr Radiol 1982;12:92-3.

4 Knox GE, Palmer MD, Huddleston JF. Fetal cystic fibrosis presenting as dystocia due to mid-gut volvulus with lethal perforation. Am J Obstet Gynecol 1978;131:698-9.

5 Nadler HL, Walsh MMJ. Intrauterine detection of cystic fibrosis. Pediatrics 1980;66:690-2.

Correspondence and requests for reprints to $\mathrm{Dr} J$ Shalev, Department of Obstetrics and Gynecology, Chaim Sheba Medical Center, Tel-Hashomer, Israel. 